\title{
Cohesive Plurality:
}

\section{Exploring the relationship between resonance and the act of writing by Jasmin Kirkbride}

\begin{abstract}
Following Peter Elbow's work on 'resonant voice' or 'presence', this essay examines the seldom-explored resonance between a text and its writer in the moment of its creation. The essay asks what the boundaries and content of this space might look like, and how this knowledge might positively affect the creative product. It challenges the popular search for a writer's 'voice', instead positing that each writer has a perpetually shifting internal plurality of voices, which unifies the constructivist and social constructionist views of the self. By arguing that the resonance between writer and writing is the experience of this plurality coming to harmony, the essay posits that to create such a resonance involves a balance of simultaneously relinquishing control to the internal choir and learning how to better conduct it.
\end{abstract}

\section{Keywords}

creative writing - writing craft - resonance - voice 


\section{Part 1: The writer's internal choir}

'Texts have no voices; they are silent. We can only talk about voice in writing by resorting to metaphor'1

In my choir at the University of East Anglia (UEA), the choirmaster will often play the first note of each part for us before starting a piece. Listening to the piano, we hum the note, wobbling momentarily up and down the scale before harmonizing. Perhaps that experience is what made Elbow's insight on the silence of texts strike me so hard; because to me, on the inside, the act of creating those silent texts creates a similar sensation to the momentary wobble of the choir. Perhaps a writer, like a choir, is always on the edge of losing the note, and simultaneously on the verge of harmony.

Elbow follows the above claim by dividing textual 'voice' into five categories: audible voice, dramatic voice, recognizable or distinctive voice, voice with authority, and resonant voice or presence. This fifth aspect is burdened by the problem that because resonance is a subjective experience for each reader of a text, 'assertions about resonant voice will always be more arguable than about other kinds of voice... enough to make some people insist that the only resonance we can talk about is between the text and the reader, not the text and the writer.' ${ }^{2}$

Yet it is precisely this resonance between text and writer which fascinates me, particularly during the process of writing. Like Elbow, I believe there is evidence for its existence. It is a

\footnotetext{
${ }^{1}$ Elbow, P. 1994:4

${ }^{2}$ Elbow, P. 1994:15
} 
secret, private resonance reserved for the writer alone, which resides outside and independent of any relationship a reader may have with a text.

There is a state of mind that writers inhabit, a space that is both intuitive and preserving: Atwood asserts 'I had to keep writing or else I would die'; ${ }^{3}$ Smith nods towards individualized forms of madness that make writing feel good to us; ${ }^{4}$ Ted Hughes posits that the act of writing provides an 'inner light'; Anne Dillard speaks of 'unmerited grace'. ${ }^{6}$ Numerous further examples point to an unexplained, almost spiritual experience found only via the conduit of the writing process. There appears to be a resonance between the writer and the text in the moment of creation.

When my writing is going well and I am in the proverbial 'zone', I feel as if I am filled with a subsonic hum, the kind you experience by lying on the floor in a choir practice room and feeling the bass notes pulse through your skin. For the writer, this vibration of skin against bass note - or, rather, 'self' against page - is what constitutes resonance.

'You are a you-all, not a singular creature, but an assemblage'"

However, though numerous writers, and notably Fulwiler, have spent many worry-stricken hours attempting to locate their "voice"8 (the 'self' of their writing), I do not think that the

\footnotetext{
${ }^{3}$ Atwood, M. 2002:xix

${ }^{4}$ For more on the imperative, see Smith, D. 2018

${ }^{5}$ Hughes, T. 2008

${ }^{6}$ Dillard, A. 1990

${ }^{7}$ Fowler, K. J. 2013:275

${ }^{8}$ Fulwiler, T. 1994
} 
resonance between writers and our texts arises from the expression of our individual, authentic voices. Raised as a Western Buddhist, I do not believe there can be a single, authentic voice, as the concept of self seems to me nothing more than an ever-morphing illusion, even now in my post-religious mindset. This has been backed up by postmodernist concerns that the idea of 'self' is no more than an illusion of 'late Romantic, bourgeois capitalism', ' though I do not even agree with this diagnosis whole-heartedly.

It seems more plausible that voice is a marriage between the presiding constructivist and social constructionist views of the self in academia. Loosely, constructivists (such as Elbow and Murray ${ }^{10}$ ) view the self as something residing within, which can be seen as authentic; social constructionists (influenced by $\mathrm{Vygotsky}^{11}$ ) deem that the self emerges primarily from without, and is an artefact resulting from social communities. ${ }^{12}$

It is possible - as Fulwiler does - to vacillate comfortably between these two opinions, but it is also possible that they are not mutually exclusive. Modern psychologists suggest that the self, while formed and cemented by external conditions and input, resides inside of us in a plurality that forms our own, relatively unique identity. A sense of identity is important - the value of the ego in psychological terms has been well recognised ${ }^{13}$ - but at any given moment we exist as countless strands of self. Shards of our parents' voices, our grandparents' admonishments, our bosses' expectations and our partners' desires all pierce our worldview and selfview, often without our noticing.

\footnotetext{
${ }^{9}$ Elbow, P. 1994:19

${ }^{10}$ As seen in Elbow, P. 1994 and Murray, D. 1984

${ }^{11}$ Vygotsky, L. 1978

${ }^{12}$ For more in-depth analysis, see Fulwiler, T. 1994:36-37

${ }^{13}$ Cote, J. E. \& Levine, C. 2002:2
} 
Similarly, this sense of identity can alter according to our external conditions. It shifts, sometimes dramatically, throughout our lives based on finances, marital status, proximity to loved ones, and numerous other social or physical circumstances. ${ }^{14}$ The effects created in our psyches are so complex and various as to make each human's consciousness remarkably individual. Each new iteration of self, which from a Buddhist perspective might be seen as a chain of perpetual deaths and rebirths, places us on a spectrum of unique or near-unique patterns of identity that are broadly similar across human nature. Our 'self' - or 'voice' - is both unique and verisimilar; predictable and changing.

Our identities are born as social constructions, but exist in a state of constructivism: plural in nature but singular in appearance.

'Narrative writers need to train their mind's ear to listen to their own prose, to hear as they write $e^{15}$

When we write, then, we may experience a sense of singular resonance, but what is happening within us is that the many voices of the self are singing in harmony, brought together to serve one creative beast. Like a choir bursting into well-practised song.

By working at our craft - and thereby learning to better access that fruitful continuity of resonance within ourselves - we become more accomplished composers of that internal choir. For example, we learn to quieten those inner critics which provide expectations that, as Cheney says, 'put the wrong kind of voices in our heads'. ${ }^{16}$ Experience tells us that an accomplished

\footnotetext{
${ }^{14}$ Weinreich, P. \& Saunderson, W. 2003:65-67;105-106

${ }^{15}$ Le Guin, U. K. 1998:2

${ }^{16}$ Cheney, M. 2013:34-35
} 
writer can not only conduct their internal choir, but audition its parts, choosing which voices they want to listen to, and thereby increasing their experience of resonance in the moment.

What's more, an accomplished writer can channel this resonance into the service of the story, successfully compressing a cohort of internal whims and voices into a cohesive whole: an illusion of singularity. They can create plots, characters and settings that feel real and whole. By creating an illusion of a whole self, a writer can create the glamour of an entire fictional universe. As a byproduct, we can also produce the 'authoritative voice' that Elbow and Cummins say is crucial to excellent writing. ${ }^{17}$

Yet, in becoming technically proficient, writers must also be careful not to cut themselves off from their internal plurality. As Cummins points out, a writer whose voice has become too authoritative - too self-aware, and therefore perhaps arrogantly divorced from the subconscious - projects into the world as a 'false mask'. ${ }^{18}$ Anzaldua agrees: 'The masks... we are compelled to wear, drive a wedge between our intersubjective personhood and the persona we present to the world... These masking roles exact a toll. ${ }^{19}$ For writers, that toll is the resonance of their work: both for themselves, and for readers. This is because readers can identify work that has been entirely severed from the unconscious and subconscious realms - not because it lacks truth, but because it does not speak to reality.

In fact, resonant writing does not necessarily need to impart truth at all, and such a thing may not be possible: if we are all pluralistic beings within, burdened with communicating via the singular voices of speech and writing, then transmitting the whole of ourselves is impossible. 'Truth' is as unattainable as singing the note of a nebula, fifty-seven octaves lower

\footnotetext{
${ }^{17}$ See Elbow, P. 1994:9-11 and Cummins, G. S. 1994:49-52

${ }^{18}$ Cummins, G. S. 1994:48-50

${ }^{19}$ Anzaldua, G. 1990:xv
} 
than middle $\mathrm{C}$ on a piano, with only the human voice: the instrument is so inadequate that it renders the task impossible.

However, as Elbow says, though 'a discourse can never fully express or articulate a whole person... words which, though they don't express or articulate everything that is in the unconscious, nevertheless somehow seem to resonate with or have behind them the unconscious as well as the conscious. ${ }^{, 20}$ In other words, writing connected to the subconscious of the author can still feel real. It nods to reality - a reality that might in some aspects be shared by a reader - creating art that 'is a lie which enables us to recognise the truth., ${ }^{21}$

This sense of reality is part of what makes up resonance between reader and text, but it cannot take place unless that initial harmony of resonance between writer and text has already happened. If the writer has severed connection to the unconscious, silencing the internal choir, then that resonance cannot be born.

'Upon the knees of ventriloquists, they own / of their dandled brightness, only the paint and board ${ }^{22}$

I wonder if even as practised, technically accomplished writers can ever truly own the resonance they seek. I suspect they cannot, in the same way that one can never truly know or own oneselves, clinging as people do to the illusions of identity that they try to create. To consciously be a 'good writer' may be impossible. As Gaiman advises, writers should instead

\footnotetext{
${ }^{20}$ Elbow, P. 1994:12

${ }^{21}$ Picasso, P. via Shields, D. 2010:32

${ }^{22}$ Klein, A. M. 1966:53
} 
allow their work to 'accrete'. ${ }^{23}$ One aspect of resonance is that parts of ourselves we are not aware of start to sing in harmony with the conscious mind. ${ }^{24}$

This holds true with Vandermeer's assertion that writing is 'an ongoing series of revelations put together by your subconscious and conscious minds working in tandem. ${ }^{25}$ Every voice singing its part, in harmony, to create a seeming whole; a rare and difficult-todefine unity of self. How much of that self belongs to us, and how much is a matter of ventriloquising the voices that we have imbibed from the world around us, is beside the point. For resonance, what matters is not ownership, but connection. To resonate with our creative drive, we must relinquish our control and fall into the external things that have made us who we are. 'Sometimes the world is more interesting than we are'26 and that is okay.

By connecting with our internal plurality, we disperse not only the self-conscious ideas that we have of ourselves in our work, but also the subconscious. As Lord suggests, the deepdive creative processes that produce resonance also create links between our work and our experiences. When resonating, we insert ourselves into our writing - often helplessly and unknowingly - in fragments scattered so sparsely and imaginatively that the story no longer resembles our own lives, and we have created something new. ${ }^{27}$

\footnotetext{
${ }^{23}$ Gaiman, N. 2013:88

${ }^{24}$ Elbow, P. 1994:12

${ }^{25}$ Vandermeer, J. 2013:1

${ }^{26}$ Robinson, K. S. 2013:56-57

${ }^{27}$ Lord, K. 2013:27
} 
'The tension between standing apart and being fully involved: that is what makes a

$$
\text { writer }^{, 28}
$$

All this is not to say that our internal choir does not need editing. Often we do need to curtail the volume of our song in order to make ourselves palatable to modern audiences and the artistic and commercial markets that swing at their whim. The complexities of internal choral politics must become one seamless whole for the song to be heard and understood. What's more, resonance that is too strong can damage, like a soprano shattering a wine glass, and our readers are not always seeking to be broken and remade when they open a book.

The composer of a choir not only has to make a choir sing, but to make it sing well, with harmony, to the score sheet before them. So, too, the challenge to writers is to present our internal resonance as one harmonious object, through the medium of the creative goals, plot and characters we have laid out before us, creating illusions of forms, worlds and individuals that might be very different from our lived experience, but will still contain a sense of resonance.

As Elbow says, 'we write best if we learn to move flexibly back and forth between on the one hand using and celebrating something we feel as our own voice, and on the other hand operating as though we are nothing but ventriloquists playfully using and adapting and working against an array of voices we find around us.' 29

The trick is to maintain a tension between losing ourselves in the song of our internal creative resonance, and stepping back to conduct our choir. A choir that practises too much will have no sparkle on stage. One that has practised too little will have difficulty singing as a cohesive, intuitive group. The writers path lies somewhere in the middle.

\footnotetext{
${ }^{28}$ Gordimer, N. 2000:4

${ }^{29}$ Elbow, P. 1994:20
} 


\section{Bibliography}

Anzaldua, G. 1990 Making Face, Making Soul = Haciendo Caras (San Francisco, CL, US: Aunt Lute)

Atwood, M. 2002 On Writers and Writing (London, UK: Virago)

Cheney, M. 2013 'Writer's Block' in Vandermeer, J. Wonderbook: The illustrated guide to creating imaginative fiction (London, UK: Abrams Image)

Cote, J. E. \& Levine, C. 2002 Identity Formation, Agency, and Culture (Mahwah, NJ, US: Lawrence Erlbaum Associates)

Cummins, G. S. 'Coming to Voice' in Yancey, K. B. (Eds) Voices on Voice: Perspectives, Definitions, Inquiry (Urbana, IL, US: National Council of Teachers of English)

Dillard, A. 1990 The Writing Life (New York, NY, US: Harper Perennial)

Elbow, P. 1994 'What do we mean when we talk about voice in text?' in Yancey, K. B. (Eds) Voices on Voice: Perspectives, Definitions, Inquiry (Urbana, IL, US: National Council of Teachers of English)

Fowler, K. J. 2013 'Finding My Way' in Vandermeer, J. Wonderbook: The illustrated guide to creating imaginative fiction (London, UK: Abrams Image)

Fulwiler, T. 1994 'Claiming my voice' in in Yancey, K. B. (Eds) Voices on Voice: Perspectives, Definitions, Inquiry (Urbana, IL, US: National Council of Teachers of English)

Gaiman, N. 2013 'The Beginning of American Gods' in Vandermeer, J. Wonderbook: The illustrated guide to creating imaginative fiction (London, UK: Abrams Image)

Gordimer, N. 2000 ‘Introduction’ in Selected Stories (London, UK: Bloomsbury) 
Hughes, T. 2008 Letters of Ted Hughes (London, UK: Farrar Straus Giroux)

Klein, A. M. 1966 'Portrait of the Poet as a Landscape' in The Rocking Chair and Other Poems (Whitby, ON, Canada: Ryerson Press)

Le Guin, U. K. 1998 Steering the Craft: A 21 ${ }^{\text {st }}$-Century Guide to Sailing the Sea of Story (New York, NY, US: Mariner Books)

Lord, K. 2013 'What is/What if: The beauty of mystery' in Vandermeer, J. Wonderbook: The illustrated guide to creating imaginative fiction (London, UK: Abrams Image)

Murray, D. 1984 Write to Learn (New York, NY, US: Holt, Rinehart \& Winston)

Robinson, K. S. 2013 ‘Thoughts on Exposition' in Vandermeer, J. Wonderbook: The illustrated guide to creating imaginative fiction (London, UK: Abrams Image)

Smith, D. 2018 'Writing and Madness' in Center for Fiction [Web: Accessed 19/4/19 http://centerforfiction.org/forwriters/writers-on-writing/writing-and-madness/]

Vandermeer, J. 2013 Wonderbook: The illustrated guide to creating imaginative fiction (London, UK: Abrams Image)

Vygotsky, L. 1978 Mind and Society (Cambridge, MA, US: Harvard University Press)

Weinreich, P. \& Saunderson, W. (Eds) 2003 Analysing Identity: Cross-Cultural, Societal and Clinical Contexts (London, UK: Routledge) 